https://doi.org/10.15407/ujpe64.3.238

O.M. ALEKSEEV, YU.F. ZABASHTA, V.I. KOVALCHUK, M.M. LAZARENKO, L.A. BULAVIN

Taras Shevchenko National University of Kyiv, Faculty of Physics (64/13, Volodymyrs'ka Str., Kyiv 01601, Ukraine)

\title{
THE STRUCTURE OF POLYMER CLUSTERS IN AQUEOUS SOLUTIONS OF HYDROXYPROPYL CELLULOSE
}

\begin{abstract}
The viscosity, turbidity, and heat capacity of dilute aqueous solutions of hydroxypropyl cellulose have been studied in a concentration interval of $0.047-1.5 \mathrm{~g} / \mathrm{l}$ and a temperature interval of 20-80 ${ }^{\circ} \mathrm{C}$. The data obtained testify that, if the temperature does not exceed $40^{\circ} \mathrm{C}$, hydroxypropyl cellulose molecules are prolate spheroidal globules with semiaxis lengths of 7 and $490 \AA$. At temperatures above $70^{\circ} \mathrm{C}$, the hydroxypropyl cellulose solution consists of clusters; every cluster is composed of 11 globules and has a prolate spheroidal form with semiaxes of 41 and $490 \AA$. In the temperature interval from 40 to $70^{\circ} \mathrm{C}$, the solution concerned contains both globules and clusters, with the concentration of the latter increasing, as the temperature grows.

Ke ywords: hydroxypropyl cellulose, globule, rigid-chain polymer.
\end{abstract}

\section{Introduction}

The formation and structure of polymer clusters in solutions is one of the key problems in colloidal physics. Those issues are dealt with in a significant number of works (see, e.g., works [1,2] and references therein).

A challenging problem in this domain is the study of mechanisms giving rise to the formation of clusters in aqueous solutions of rigid-chain polymers. It is well known [1] that the chains of these polymers can be considered as a set of segments, i.e., rods that are characterized by a considerable rigidity and a definite length and linked to one another. For this reason, the aqueous solutions of rigid-chain polymers tend to form clusters, in which those rods are arranged in parallel to one another and, in effect, are nuclei of liquid-crystal structures.

(C) O.M. ALEKSEEV, YU.F. ZABASHTA,

V.I. KOVALCHUK, M.M. LAZARENKO,

L.A. BULAVIN, 2019

238
When studying the properties of solutions of rigidchain polymers, the solutions of cellulose derivatives are analyzed, as a rule. For instance, the formation of clusters of rigid-chain polymers in rather concentrated aqueous solutions - in other words, in the systems that already contained clusters - was studied, e.g., in works [3-5]. However, the mechanism of polymer cluster formation has not been discussed at that.

In this work, dilute aqueous solutions of hydroxypropyl cellulose have been studied in order to elucidate this issue.

\section{Experimental Part}

As a research object, hydroxypropyl cellulose was selected. Its IR spectrum is presented in Fig. 1 (spectrum 2). For comparison, this figure also demonstrates the IR spectrum of reference hydroxypropyl cellulose (Alfa Aesar) (spectrum 1). For convenience, spectrum 2 in Fig. 1 is shifted vertically by 0.2 with respect to spectrum 1 . The both spectra were registered for powder specimens in an interval of 460-

ISSN 2071-0194. Ukr. J. Phys. 2019. Vol. 64, No. 3 
$4000 \mathrm{~cm}^{-1}$ on a Nicolet Nexus 470 Fourier spectrometer and making use of a Smart Orbit device (Thermo Scientific).

One can see that the spectra of both hydroxypropyl cellulose specimens are almost identical. Therefore, we consider their molecular masses and substitution degrees to be also close. For reference hydroxypropyl cellulose (spectrum 1), the molecular weight was $10^{5}$, and the substitution degree was $75.7 \%$.

In order to study the viscosity, turbidity, and heat capacity of dilute aqueous solutions of hydroxypropyl cellulose, we prepared solutions with hydroxypropyl cellulose concentrations $c=0.094,0.185,0.375,0.75$, and $1.5 \mathrm{~g} / \mathrm{l}$.

The shear viscosity of the hydroxypropyl cellulosewater systems was determined in a temperature interval of $20-80^{\circ} \mathrm{C}$. For measurements, we used a capillary viscometer with a vertical capillary and a thermostatic system. Figure 2 illustrates the measurement results obtained for the temperature-dependent shear viscosity of the solution under study. The data in this figure were used to plot the dependence of the relative viscosity of the solution $\eta^{\prime}=\eta / \eta_{0}$, where $\eta_{0}$ is the viscosity of water, on the volume polymer concentration $\phi=c / \rho$, where $\rho=1.27 \mathrm{~g} / \mathrm{cm}^{3}$ is the density of hydroxypropyl cellulose [6] (see Fig. 3). Approximating this dependence by the polynomial

$\eta^{\prime}(\phi)=1+b_{1} \phi+b_{2} \phi^{2}+\ldots$

we obtained the temperature dependence of the coefficient $b_{1}$ in formula (1), which is shown in Fig. 4.

The turbidity of the aqueous solutions of hydroxypropyl cellulose was measured at various temperatures on an installation, whose schematic diagram

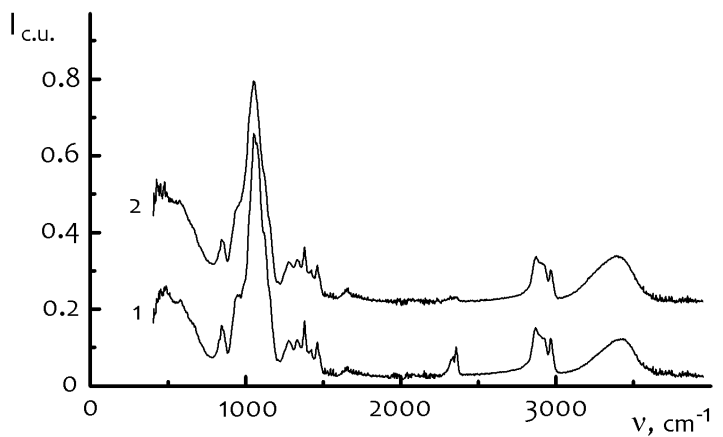

Fig. 1. IR spectra of frustrated total internal reflection in the specimens: reference hydroxypropyl cellulose (1), our specimen (2)

ISSN 2071-0194. Ukr. J. Phys. 2019. Vol. 64, No. 3

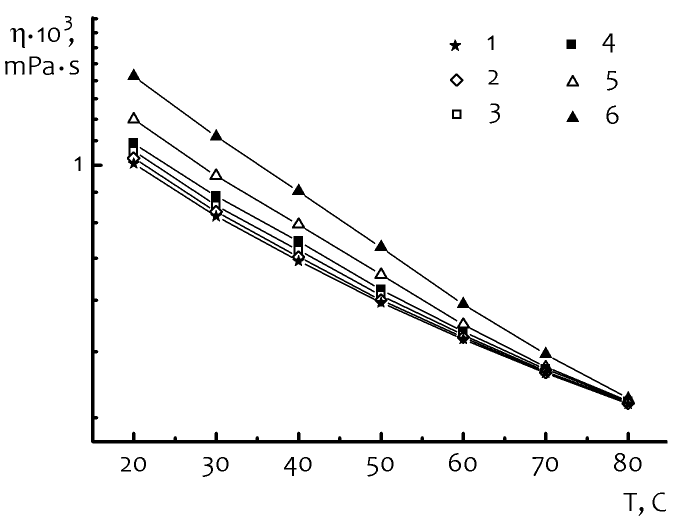

Fig. 2. Temperature dependences of shear viscosity in hydroxypropyl cellulose-water systems with various hydroxypropyl cellulose concentrations: (1) 0.047 , (2) 0.094, (3) 0.185 , (4) 0.375 , (5) 0.75 , and (6) $1.5 \mathrm{~g} / \mathrm{l}$

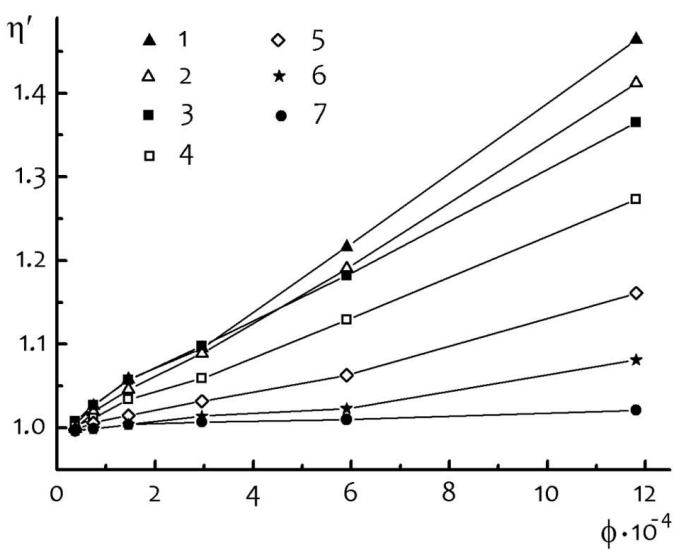

Fig. 3. Dependences of the relative viscosity in hydroxypropyl cellulose-water systems on the bulk concentration of hydroxypropyl cellulose at various temperatures: 20 (1), 30 (2), 40 (3), 50 (4), $60(5), 70(6)$, and $80{ }^{\circ} \mathrm{C}(7)$

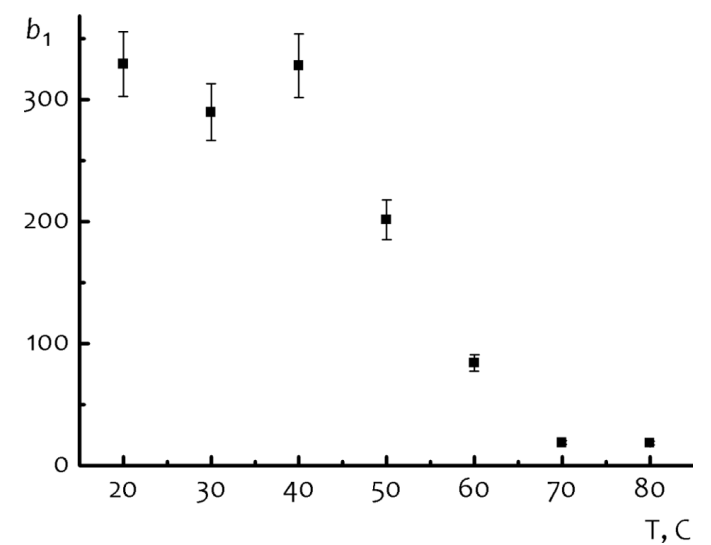

Fig. 4. Temperature dependence of the coefficient $b_{1}$ in formula (1) for hydroxypropyl cellulose-water systems 


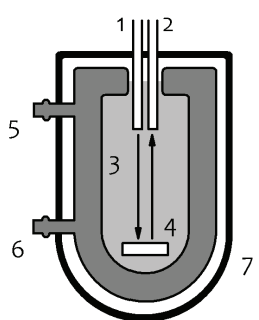

Fig. 5. Schematic diagram of the installation for turbidity measurements: fiber optic cables (1, 2), thermostat chamber (3), mirror (4), nipples for connection with thermostat $(5,6)$, light-proof housing ( 7$)$

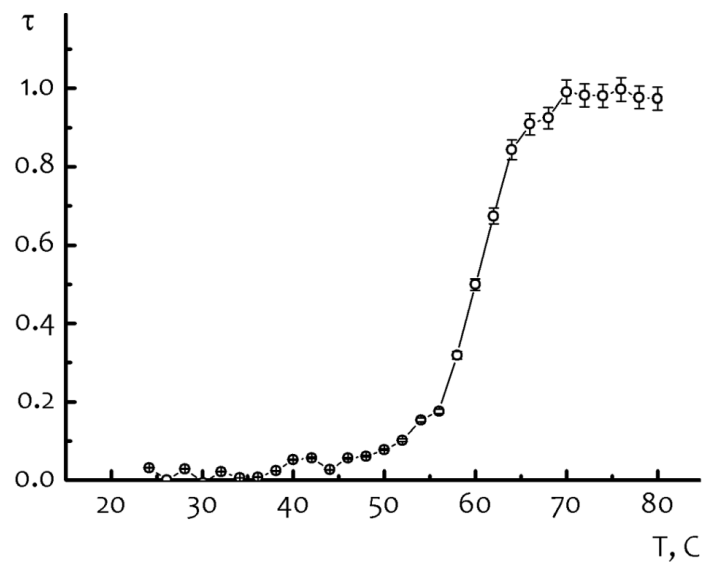

Fig. 6. Temperature dependence of the relative turbidity in the hydroxypropyl cellulose-water system (at the concentration $c=1.5 \mathrm{~g} / \mathrm{l})$

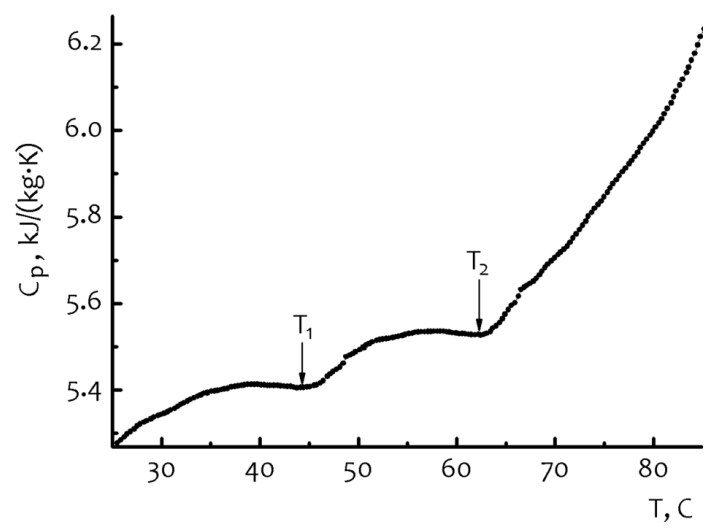

Fig. 7. Temperature dependence of the specific heat for the hydroxypropyl cellulose-water system (at the concentration $c=$ $1.5 \mathrm{~g} / \mathrm{l})$

is exhibited in Fig. 5. As a light source and a light detector, we used the corresponding semiconductor devices G-Nor GNL-5013 and Osram SFH-203 with known spectral characteristics. Light with a wave- length of about $5500 \AA$ was supplied with the help of a fiber optic cable 1 into a thermostatically controlled chamber 3 filled with the polymer solution. Being reflected from mirror 4, the light beam returned to the photodetector. The resulting photo current was amplified using a low-noise operational amplifier OPA128LM. The relative turbidity of the solution was determined by the formula

$\tau=\frac{V_{0}-V}{V_{0}-V_{d}}$

where $V_{0}, V$, and $V_{d}$ are voltages at the amplifier output corresponding to measurements with distilled water, polymer solution, and at complete photo detector shading, respectively. A typical temperature dependence of the turbidity of the examined solution is depicted in Fig. 6.

The specific heat at a constant pressure, $C_{p}$, was measured following the method described in work [7]. Using a dynamic calorimeter which registered changes in the heat flow entering the specimen, the temperature dependence of $C_{p}$ was obtained for the aqueous solution of hydroxypropyl cellulose with the concentration $c=1.5 \mathrm{~g} / \mathrm{l}$ in a temperature interval of $25-85{ }^{\circ} \mathrm{C}$ (Fig. 7 ). The rate of specimen heating was $2 \mathrm{~K} / \mathrm{min}$. The relative measurement error did not exceed $3 \%$. From the analysis of experimental data presented in Fig. 7, it follows that the temperature dependence of $C_{p}$ has two exothermic minima at the specimen temperatures $T_{1}=44{ }^{\circ} \mathrm{C}$ and $T_{2}=60{ }^{\circ} \mathrm{C}$.

\section{Discussion of Experimental Results}

While interpreting the experimental results, we applied the hydrodynamic theory of solutions [8]. In the framework of this theory, the solution is considered as a two-component system consisting of a liquid matrix (the solvent), in which solid inclusions of the dissolved substance are located.

Let us firstly assume that the inclusions are spherical. As was shown by A. Einstein [8], the coefficient $b_{1}$ in formula (1) should have been equal to 2.5 in this case. However, as one can see from Fig. 4, the experimentally obtained $b_{1}$-values substantially exceed the indicated value. Hence, the inclusions in the matrix arenot spherical.

Then we assume that the inclusions are prolate ellipsoids of revolution (spheroids). In this case, the following formulas are valid [9]: 
at $1<p<15$

$b_{1}=2.5+0.4075(p-1)^{1.508}$;

and at $p>15$,

$b_{1}=1.6+\frac{p^{2}}{5}\left[\frac{1}{3(\ln 2 p-1.5)}+\frac{1}{\ln 2 p-0.5}\right]$,

where $p=a_{1} / a_{2}$, and $a_{1}$ and $a_{2}$ are the lengths of the large and small, respectively, semiaxes of the spheroid. The values of the parameter $p$ calculated by formulas (3) and (4) are shown in Fig. 8. An analysis of this figure allows three temperature intervals to be distinguished:

- $T<40{ }^{\circ} \mathrm{C}$; here, the value of $p$ is constant and approximately equals 70 );

- $40^{\circ} \mathrm{C}<T<70{ }^{\circ} \mathrm{C}$; the value of $p$ decreases with the temperature growth; and

- $T>70{ }^{\circ} \mathrm{C}$; the value of $p$ is invariable again and equals 12 .

Since the dilute solutions are studied, it is reasonable to assume that, within the interval $T<40^{\circ} \mathrm{C}$, the dissolved substance exists in the form of isolated molecules. In a dilute solution of flexible-chain polymers, the molecules of the substance form a statistical ball under definite conditions. If the chains are rigid, the existence of this form is problematic. As was already noted, for the researched objects, $b_{1} \gg 1$, so that an inclusion (in this case, a molecule) is not spherical. Therefore, the molecules in the examined solutions are not statistical balls.

Let the hydroxypropyl cellulose molecule have a completely stretched form. The molecular weight of this polymer is of an order of $10^{5}$. The molecular weight of the glucose residue is 162 . Every elementary link includes two such residues. Therefore, there are approximately 300 links in the complete chain (the molecule).

Using the data for the crystal lattice parameters of cellulose [6], we obtain values of 10 and $8 \AA$ for the link length and width, respectively. Accordingly, the length of the completely stretched chain is about $3000 \AA$. If the chain has a prolate spheroidal form, the lengths of its semiaxes equal $a_{1}=1500 \AA$ and $a_{2}=4 \AA$, so that $p \approx 370$, which differs substantially from our experimental value. Hence, the hydroxypropyl cellulose molecule is not a completely stretched chain in the solution. Thus, we should

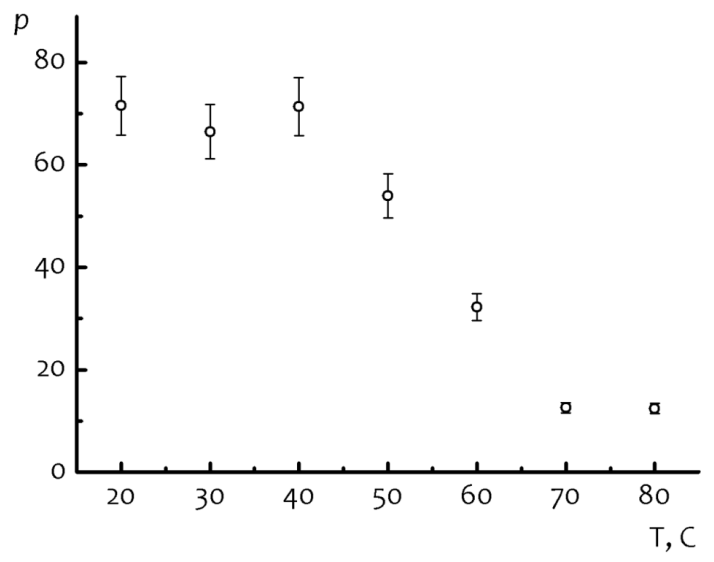

Fig. 8. Temperature dependence of the ratio between the semiaxis lengths of a spheroid of inclusions

a)

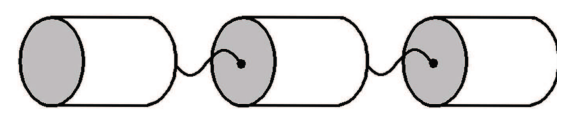

b)

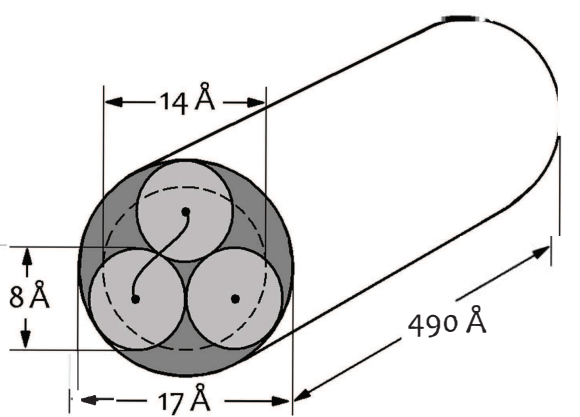

Fig. 9. Schematic diagram of the globule formation: a chain of rigid blocks connected by flexible crosspieces $(a)$, packing of blocks into a globule $(b)$

adopt that the molecular chain is packed into an elongated globule.

Hydroxypropyl cellulose is known to be formed by substituting atoms in the lateral cellulose groups, As a result, the hydrogen bonds that connect neighbor glucose residues become destroyed, and the chain becomes flexible at this sites. In accordance with this mechanism, the chain of the hydroxypropyl cellulose molecule can be imagined as a sequence of rigid blocks connected by flexible crosspieces (Fig. 9, a). A globule is formed owing to the chain bending at the crosspieces and the packing of blocks close to one another.

Let us evaluate the size of the formed globule. According to the assumption made above, the globule is spheroidal by its form. Let $h_{1}$ and $h_{2}$ denote the lengths of the major and minor, respectively, semi- 
axes of this spheroid. The volume occupied by the molecule equals

$V_{\mathrm{M}}=\frac{4 \pi}{3} a_{1} a_{2}^{2}$,

and the volume occupied by the globule

$V_{\mathrm{G}}=\frac{4 \pi}{3} h_{1} h_{2}^{2}$.

It is reasonable to assume those volumes identical, $V_{\mathrm{M}}=V_{\mathrm{G}}$, so that

$a_{1} a_{2}^{2}=h_{1} h_{2}^{2}$.

As was already mentioned above, according to our experimental data, $p=h_{1} / h_{2} \approx 70$ in the analyzed temperature interval. Then, Eq. (7) reads

$a_{1} a_{2}^{2}=70 h_{2}^{3}$.

After substituting the $a_{1}$ - and $a_{2}$-values given above into formula (8), we obtain $h_{2}=7 \AA$ and, accordingly, $h_{1}=490 \AA$.

The model of a globule with the indicated dimensions is shown in Fig. 9, $b$. The figure demonstrates a half of the spheroid that models the globule: the dashed circle with the diameter $2 h_{2}=14 \AA$ determines the boundaries of the spheroid profile. As one can see from Fig. 9, $b$, the ellipsoid surface is a smoothed globule boundary. This smoothing is a result of equating the volumes of the globule and the chain molecule that forms this globule (see Eqs. (5)(7)). The polymer chain partially extends beyond the smoothed boundary, as is shown in Fig. 9, b. A circle that encircles those bulges has a diameter of $17 \AA$.

If considering a spheroid characterized by the parameter $p=70$ as a globule, it is reasonable to assert that a spheroid with $p=12$ is a cluster formed from the globules by means of their merging. This model allows us to talk about two phase states of the solution:

- at $T<40{ }^{\circ} \mathrm{C}$, stable is the solution phase, in which the polymer chain looks like a globule (hereafter, the low-temperature phase);

- at $T>70{ }^{\circ} \mathrm{C}$, stable is the solution phase, in which the globules are grouped into clusters (hereafter, the high-temperature phase);

- at $40{ }^{\circ} \mathrm{C}<T<70{ }^{\circ} \mathrm{C}$, the both indicated phases coexist.
The presence of a phase transition in the solution is also confirmed by a minimum in the temperature dependence of the specific heat capacity at $40{ }^{\circ} \mathrm{C}$ (see Fig. 7).

The described model for the structure of a hydroxypropyl cellulose solution, which follows from the temperature dependence of the parameter $p$ (Fig. 8), is confirmed by the temperature dependence of the relative turbidity (Fig. 6). Here, three temperature intervals can be distinguished as well:

- the turbidity is stable at $T<40{ }^{\circ} \mathrm{C}$;

- in the interval $40{ }^{\circ} \mathrm{C}<T<70{ }^{\circ} \mathrm{C}$, the turbidity increases with the temperature;

- at $\mathrm{T}>70^{\circ} \mathrm{C}$, the turbidity also has a constant value that substantially exceeds the value at $T<40{ }^{\circ} \mathrm{C}$.

Thus, the logic of our speculations is not violated: the growth in the concentration of clusters in a liquid system leads to the growth of its turbidity.

Let $H_{1}$ and $H_{2}$ denote the lengths of the major and minor, respectively, semiaxes of a spheroidal cluster. When constructing the latter, it is thermodynamically beneficial for the globules to form a structure that would be the densest among all possible ones. This requirement is satisfied at such a globule packing, when the major semiaxes of the globules are oriented in parallel to one another, and the following condition is obeyed:

$H_{1}=h_{1}$.

Let $n$ be the number of globules in the cluster. Assuming that, when a globule is formed, the chain is folded three times (see Fig. 9), the profile area of the spheroidal cluster is described by the formula

$\pi H_{2}^{2}=3 n \pi a_{2}^{2}$.

Since, as was determined experimentally, $H_{1} / H_{2}=$ $=12$, Eqs. (9) and (10) imply that $H_{1}=490 \AA$, $H_{2}=41 \AA$ and $n=11$.

The globule and cluster models that are discussed here were constructed on the basis of viscosimetric experimental data. Let us verify whether those models agree with the turbidity data.

Let $J_{1}$ and $J_{2}$ denote the intensities of light scattering in the temperature intervals $T<40{ }^{\circ} \mathrm{C}$ and $T>70{ }^{\circ} \mathrm{C}$, respectively; $\sigma_{1}$ and $\sigma_{2}$ the scattering cross-sections for a globule and a cluster, respectively; and $n_{1}$ and $n_{2}$ the bulk concentrations of globules and 
clusters, respectively. Those quantities are connected by the known dependence [10]

$J_{1,2}(x)=J_{0} \exp \left(-\sigma_{1,2} n_{1,2} x\right)$,

where $x$ is the path length passed by light, and $J_{0}$ the intensity of the initial beam. Let us rewrite relation (11) in the form

$q_{1,2}(x)=-\sigma_{1,2} n_{1,2} x$,

where $q_{1,2}=\ln \left(J_{1,2} / J_{0}\right)$.

As was marked above, the turbidity plot in Fig. 6 corresponds to the polymer mass concentration in the solution $c=1.5 \mathrm{~g} / \mathrm{l}$. The mass of a hydroxypropyl cellulose molecule (a globule) equals $m_{1}=10^{5} \times 1.67 \times$ $\times 10^{-24} \mathrm{~g}$. Hence, $n_{1}=c / m_{1}=4.9 \times 10^{16} \mathrm{~cm}^{-3}$. As was found in our viscosimetric experiment, one cluster consists of 11 globules. For the bulk cluster concentration, we have $n_{2}=n_{1} / 11=4.5 \times 10^{15} \mathrm{~cm}^{-3}$. The average values of the parameters $q_{1}$ and $q_{2}$, which were determined from the experimental dependence in Fig. 6, equal -0.033 and -4.117 , respectively. The path length $x$ in the experimental installation was $7.5 \mathrm{~cm}$. Substituting the obtained numerical values of $q_{1}, q_{2}, x, n_{1}$, and $n_{2}$ into Eq. (12), we obtain $\sigma_{1}=4.9 \times 10^{-19} \mathrm{~cm}^{2}$ and $\sigma_{1}=6.7 \times 10^{-15} \mathrm{~cm}^{2}$.

Let us approximately assume that an ellipsoid of revolution scatters light identically as a sphere with the same volume does. Using the known expressions for the ellipsoid and sphere volumes

$\frac{4 \pi}{3} h_{1} h_{2}^{2}=\frac{4 \pi}{3} r_{1}^{3}$,

$\frac{4 \pi}{3} H_{1} H_{2}^{2}=\frac{4 \pi}{3} r_{2}^{3}$

together with the values for $h_{1}, h_{2}, H_{1}$, and $H_{2}$ determined fron the viscosimetric experiment, we obtain the following values for the radii of relevant spheres: $r_{1}=2.8 \times 10^{-7} \mathrm{~cm}$ and $r_{2}=9.4 \times 10^{-7} \mathrm{~cm}$.

In our experiment, the light wavelength was about $5500 \AA$. Hence, for the wave vector magnitude, we obtain $k=1.1 \times 10^{5} \mathrm{~cm}^{-1}$. Therefore, the condition $k r_{1,2} \ll 1$ is satisfied. In this case, the following relation is valid:

$\sigma_{1,2} \sim r_{1,2}^{2}\left(k r_{1,2}\right)^{4}$,

and, thus, the equality

$\left(\frac{\sigma_{1}}{\sigma_{2}}\right)^{1 / 6}=\frac{r_{2}}{r_{1}}$. must be obeyed. The ratio $r_{2} / r_{1}$ determined from the data of the viscometric experiment equals 3.4. At the same time, the value of $\left(\sigma_{1} / \sigma_{2}\right)^{1 / 6}$ equals 4.7 . In view of the assumptions made in calculations, this difference should be considered, in our opinion, as negligibly small. Therefore, we may assume that the mechanism of cluster formation proposed by us agrees with the experimental turbidity data.

\section{Conclusions}

Dilute aqueous solutions of hydroxypropyl cellulose with concentrations lower than $c=1.5 \mathrm{~g} / \mathrm{l}$ can exist in two phase states. The low-temperature phase exists in the temperature interval $T<40{ }^{\circ} \mathrm{C}$, and the high-temperature one in the interval $T>70{ }^{\circ} \mathrm{C}$. At $40{ }^{\circ} \mathrm{C}<T<70{ }^{\circ} \mathrm{C}$, the both phases coexist.

In the low-temperature phase, the hydroxypropyl cellulose solution is a set of separate chains. In this case, every chain forms a prolate spheroidal globule with semiaxis lengths of 490 and $7 \AA$. In the hightemperature phase, the globules are packed into clusters. Every cluster contains 11 globules. In this case, the clusters are also prolate spheroids, but with semiaxis lengths of 490 and $41 \AA$.

1. A.R. Khokhlov, A.Yu. Grosberg. Statistical Physics of Macromolecules (AIP Press, 1994) [ISBN: 9781563960710].

2. Rheology. Vol. 5: Theory and Applications. Edited by F.R. Eirich (Academic Press, 2014) [ISBN: 9781483252674].

3. S. Fortin, G. Charlet. Phase diagram of aqueous solutions of (hydroxypropyl)cellulose. Macromolecules 22, 2286 (1989).

4. S. Guido. Phase behavior of aqueous solutions of hydroxypropyl cellulose. Macromolecules 28, 4530 (1995).

5. Y. Guan, Y. Zhang, T. Zhoua, S. Zhou. Stability of hydrogen-bonded hydroxypropylcellulose/poly(acrylic acid) microcapsules in aqueous solutions. Soft Matter 5, 842 (2009).

6. Hydroxypropyl cellulose [https://www.guidechem.com/ dictionary/en/9004-64-2.html].

7. O.M. Alekseev, M.M. Lazarenko, G.O. Puchkovs'ka, T.V. Bezrodnaya, A.A. Sendzyuk. Peculiarities of the thermal motion in crystals formed by cetyltrimethylammonium bromide molecules. Ukr. J. Phys. 55, 973 (2010).

8. L.D. Landau, E.M. Lifshitz. Course of Theoretical Physics. Vol. 6: Fluid Mechanics (Elsevier, 2013) [ISBN: 9780750627672].

9. W. Kuhn, H. Kuhn. Die Abhängigkeit der Viskosität vom Strömungsgefälle bei hochverdünnten Suspensionen und Lösungen. Helv. Chim. Acta. 28, 97 (1945). 
10. C.F. Bohren, D.R. Huffman. Absorption and Scattering of Light by Small Particles (Wiley, 1998) [ISBN: 978-0-47129340-8].

Received 03.11.18.

Translated from Ukrainian by O.I. Voitenko

О.М. Алєксєев, Ю.Ф. Забашта,

В.І. Ковалъчук, М.М. Лазаренко, Л.А. Булавін

СТРУКТУРА КЛАСТЕРІВ У ВОДНИХ

РОЗЧИНАХ ГІДРОКСИПРОПІЛЦЕЛЮЛОЗИ

$\mathrm{P}$ е $з$ ю м е

Досліджено в'язкість, мутність і теплоємність розбавлених водних розчинів гідроксипропілцелюлози в інтервалі кон- центрацій $(0,047-1,5)$ г л і інтервалі температур (20-80) ${ }^{\circ} \mathrm{C}$. На підставі отриманих даних встановлено, що при температурі, меншій від $40{ }^{\circ} \mathrm{C}$, молекули гідроксипропілцелюлози є глобулами, які мають форму еліпсоїда обертання 3 довжинами напівосей $7 \AA$ і $490 \AA$. При температурах, вищих за $70{ }^{\circ} \mathrm{C}$, розчин гідроксипропілцелюлози складається 3 кластерів, кожен з яких містить в своєму складі 11 глобул і має форму еліпсоїда обертання з напівосями $41 \AA$ i $490 \AA$ А. В температурному інтервалі $(40-70){ }^{\circ} \mathrm{C}$ в розчині гідроксипропілцелюлози одночасно містяться як глобули, так і кластери. Кількість останніх зростає зі збільшенням температури. 